\title{
Treatment of Color Filter Wastewater by Fresnel Lens Enhanced Solar Photo-Fenton Process
}

\author{
Wen-shiuh Kuo and Chia-ling Wu \\ Department of Safety, Health, and Environmental Engineering, National United University, Miao-Li 36063, Taiwan \\ Correspondence should be addressed to Wen-shiuh Kuo, wsk@nuu.edu.tw
}

Received 17 February 2012; Accepted 27 March 2012

Academic Editor: Yu-Pei Huang

Copyright ( $) 2012$ W.-s. Kuo and C.-1. Wu. This is an open access article distributed under the Creative Commons Attribution License, which permits unrestricted use, distribution, and reproduction in any medium, provided the original work is properly cited.

\begin{abstract}
Treatment of color filter wastewater using solar photo-Fenton process enhanced by high-concentrating Fresnel lens was investigated in this paper. Optimal reaction conditions based on response surface methodology (RSM) were established as under an initial $\mathrm{pH}$ of $5, \mathrm{a}\left[\mathrm{H}_{2} \mathrm{O}_{2}\right]_{0} / \mathrm{COD}_{0}$ ratio of $1 \sim 1.35$ and a $\left[\mathrm{H}_{2} \mathrm{O}_{2}\right]_{0} /\left[\mathrm{Fe}^{2+}\right]_{0}$ ratio of 15 for a reaction time of 60 min, which could reach a readily biodegradable level, that is, the biodegradability $\left(\mathrm{BOD}_{5} / \mathrm{COD}\right)$ of wastewater was more than 0.3 . With the assistance of Fresnel lens, the solar photo-Fenton process increased the COD degradation rate and mineralization rate by a factor of 4.5 and 6.5 , respectively. In addition, the microtoxicity $\left(\mathrm{TU}_{50}\right)$ of wastewater was almost diminished after a 60 min of treatment, whereas the microtoxicity of treated wastewater without the assistance of Fresnel lens remained a $\mathrm{TU}_{50}$ value of 1.166. This could be mainly due to the concentrating effect of Fresnel lens for solar energy, resulting in an increase of $2 \sim 3$ times of solar light intensity and a raising heat irradiation in terms of $15 \sim 30^{\circ} \mathrm{C}$ of wastewater temperature. These results revealed that solar energy could be concentrated effectively by using Fresnel lens and showed a significant promoting effect on the photo-Fenton reaction for treating color filter wastewater.
\end{abstract}

\section{Introduction}

Organic wastewater from color filter industry generally contains so many residuals such as TMAH $\left(\mathrm{C}_{4} \mathrm{H}_{13} \mathrm{NO}\right)$, PGMEA $\left(\mathrm{C}_{6} \mathrm{H}_{12} \mathrm{O}_{3}\right)$, acrylic resin, and pigments, and it is variable in composition and strength at different stages of process. The effluent is usually characterized by its high chemical oxygen demand (COD), low biodegradability $\left(\mathrm{BOD}_{5} / \mathrm{COD}\right)$, and with microtoxicity, implying the presence of refractory organic matter. Therefore, biological treatment processes are susceptible for treatment of color filter wastewater. Instead, activated carbon adsorption or coagulation is commonly used. However, new environmental laws may consider the spent adsorbents or sludge as hazardous waste and require further treatment. Consequently, intensive research for novel technologies with higher efficiency and less amount of waste generated has been stimulated. For that reason, advanced oxidation processes (AOPs) have been previously described as a promising option to remove persistent pollutants from contaminated water [1] when conventional water treatment processes are not efficient enough. AOPs are able to produce a highly reactive, nonspecific oxidant, mainly hydroxyl radicals $\left({ }^{\bullet} \mathrm{OH}\right)$. The hydroxyl radical possesses inherent properties that enable it to attack refractory organic pollutants in water to achieve a complete mineralization. However, the production of photons with artificial light sources requires significant electrical energy demand and UV lamp consumption, leading in a high operation cost in AOPs [2].

Alternatively, solar energy is essentially unlimited and its utilization is ecologically benign. In the wastewater treatment sector, solar technology has been extensively used as alternative to UV lamps to reduce the operation cost in AOPs [3]. In particular, photo-Fenton process using solar irradiation has been used as an economically viable process and has attracted great interest in recent years [4]. However, solar photo-Fenton process was usually carried out by using solar irradiation directly, resulting in a lower absorption and utilization of solar energy [5]. To improve the efficiency of solar photo-Fenton process, it is necessary to maximize the absorption of solar energy. 
TABLE 1: Characteristics of color filter wastewater.

\begin{tabular}{lc}
\hline Item & Range \\
\hline $\mathrm{pH}$ & $10.4 \sim 10.7$ \\
$\mathrm{UV}_{254}$ & $2.000 \sim 2.046$ \\
$\mathrm{COD}, \mathrm{mg} / \mathrm{L}$ & $1674 \sim 1766$ \\
$\mathrm{BOD}_{5}, \mathrm{mg} / \mathrm{L}$ & $152 \sim 230$ \\
$\mathrm{BOD}_{5} / \mathrm{COD}$ & $0.08 \sim 0.13$ \\
$\mathrm{TOC}, \mathrm{mg} / \mathrm{L}$ & $405 \sim 430$ \\
$\mathrm{SS}, \mathrm{mg} / \mathrm{L}$ & $2.4 \sim 3.0$ \\
$\mathrm{TS}, \mathrm{mg} / \mathrm{L}$ & $1145 \sim 1440$ \\
$\mathrm{Color}(\mathrm{ADMI}$ value $)$ & $1100 \sim 1400$ \\
\hline
\end{tabular}

In this study, the degradation and mineralization of color filter wastewater using solar photo-Fenton process enhanced by high-concentrating Fresnel lens was investigated. This lens is made of PMMA plastic materials. Response surface methodology (RSM) was employed to obtain the optimal reaction conditions of critical process parameters (initial $\mathrm{pH}$ of wastewater, $\left[\mathrm{H}_{2} \mathrm{O}_{2}\right]_{0} / \mathrm{COD}_{0}$ and $\left.\left[\mathrm{H}_{2} \mathrm{O}_{2}\right]_{0} /\left[\mathrm{Fe}^{2+}\right]_{0}\right)$ to reach a readily biodegradable degree of color filter wastewater. Moreover, the effect of Fresnel lens on treatment performance in terms of COD degradation efficiency, mineralization efficiency, biodegradability, and microtoxicity of color filter wastewater was examined.

\section{Materials and Methods}

2.1. Materials. The color filter wastewater used in this study was obtained from an electrooptical industry plant located in Hsin-Chu, Taiwan. The characteristics of color filter waster are shown in Table 1. Basically, the color filter wastewater has the properties of high COD, low biodegradability, and with microtoxicity. Hydrogen peroxide $\left(\mathrm{H}_{2} \mathrm{O}_{2}\right)$ with a concentration of $35 \%$ was supplied by Panreac Co., EU. $\mathrm{FeSO}_{4} \cdot 7 \mathrm{H}_{2} \mathrm{O}$ (Panreac Co., EU) with a purity of $99 \%$ was used as a source of ferrous ion. All other chemicals used in this study were analytical grade and used as received.

2.2. Procedures. All experiments were carried out in a batch mode. A 1-L glass beaker containing $200 \mathrm{~mL}$ of color filter wastewater was used and maintained at a preset temperature in a water bath during the experiments. A 3-factor *3-level RSM experimental design with three replicates at center point as shown in Table 2 was applied. The color filter wastewater was placed into the photoreactor and irradiated by artificial solar light with an intensity of $500 \mathrm{~W} / \mathrm{m}^{2}$ by using an ATLAS Suntest CPS+ solar simulator (ATLAS Co., USA). During the experiments, the $\mathrm{pH}$ of the solution was monitored using a pH meter (SP-701LI 120, Suntex Co., Taiwan) equipped with a glass electrode. Samples were withdrawn from the reactor at a reaction time of $60 \mathrm{~min}$, tested for $\mathrm{H}_{2} \mathrm{O}_{2}$ consumption according to the method reported by Seller [6] and iron as $\mathrm{Fe}^{2+}$ ion determined by $\mathrm{Fe}(\mathrm{II}) / 1,10$-phenanthroline complex at $510 \mathrm{~nm}$ [7] using a Hitachi (Japan) U-2001 spectrophotometer instantly, and then quenched with sodium hydrogen sulfite to avoid further
TABLE 2: Experimental range and levels of the process independent variables in this study.

\begin{tabular}{lcccc}
\hline Independent variable & Factor & \multicolumn{3}{c}{ Range and level } \\
& & -1 & 0 & +1 \\
\hline Initial pH & $X_{1}$ & 3 & 4 & 5 \\
$\mathrm{~g} \mathrm{H}_{2} \mathrm{O}_{2} / \mathrm{g} \mathrm{COD}^{+2}$ & $X_{2}$ & 1.0 & 1.5 & 2.0 \\
{$\left[\mathrm{H}_{2} \mathrm{O}_{2}\right]_{0} /\left[\mathrm{Fe}^{+2}\right]_{0}$} & $X_{3}$ & 5 & 10 & 15 \\
\hline
\end{tabular}

reactions. The remaining samples were then stored at $4^{\circ} \mathrm{C}$ for the following $\mathrm{ADMI}, \mathrm{COD}, \mathrm{TOC}, \mathrm{BOD}_{5}$, and microtoxicity analysis.

As the optimal values of the process parameters were developed on the basis of RSM application and related equations, a Fresnel lens that was made of PMMA (thickness: $2 \mathrm{~mm}$, pitch: $0.5 \mathrm{~mm}$, facet depth: $0.2 \mathrm{~mm}$, Fresnel circles: 395) was added into solar photo-Fenton system with a distance of $16 \mathrm{~cm}$ above the level of wastewater. To investigate the effect of Fresnel lens, a similar reactor without Fresnel lens was also performed under the same actual solar irradiation. A schematic diagram of the photoreactor using Fresnel lens is shown in Figure 1.

\subsection{Analytical Methods}

2.3.1. Color Measurement of Color Filter Wastewater. A DR 4000 spectrophotometer (HACH Co., USA) was used for color measurement in terms of ADMI (American Dye Manufacturers Institute) values. The decolorization efficiency was calculated on the basis of ADMI reduction in color filter wastewater.

2.3.2. COD and TOC Measurement. COD (Chemical Oxygen Demand) of wastewater was carried out via a DR 4000 photometer (HACH Co., USA) by using a $\mathrm{K}_{2} \mathrm{Cr}_{2} \mathrm{O}_{7}$ reagent. TOC (Total Organic Carbon) of wastewater was measured by a Shimadzu VCPH analyzer (Shimadzu Co., Japan).

2.3.3. $\mathrm{BOD}_{5}$ Measurement. $\mathrm{BOD}_{5}$ test was measured according to the procedures described in Standard methods [7] Section 5210D. The bacteria (2000 4000 mgMLSS/L) used in this test were obtained from local activation sludge system, operating at industrial wastewater treatment plant. The data showed that the $\mathrm{BOD}_{5}$ value of untreated color filter wastewater in this study was $0.08 \sim 0.13$, indicating that the color filter wastewater was not readily biodegradable.

2.3.4. Microtoxicity Measurement. The microtoxicity of each sample was measured using an SDI M500 (SDI Co., USA) analyzer. Microtoxicity is expressed as $\operatorname{EC}_{50}\left(5 \mathrm{~min}, 15^{\circ} \mathrm{C}\right)$, which was defined as the effective concentration of solution for a $50 \%$ reduction of the luminescence of the bacterium Photobacterium phosphoreum. A lower $\mathrm{EC}_{50}$ value indicates a higher amount of toxic constituent presented in the pollutant solution. The $\mathrm{EC}_{50}$ values are expressed as percentage (\% $\mathrm{v} / \mathrm{v}$ ) of the sample $[8,9]$. In addition, $\mathrm{EC}_{50}$ values could be transformed to toxicity units $\left(\mathrm{TU}_{50}\right)$, which was equal to 


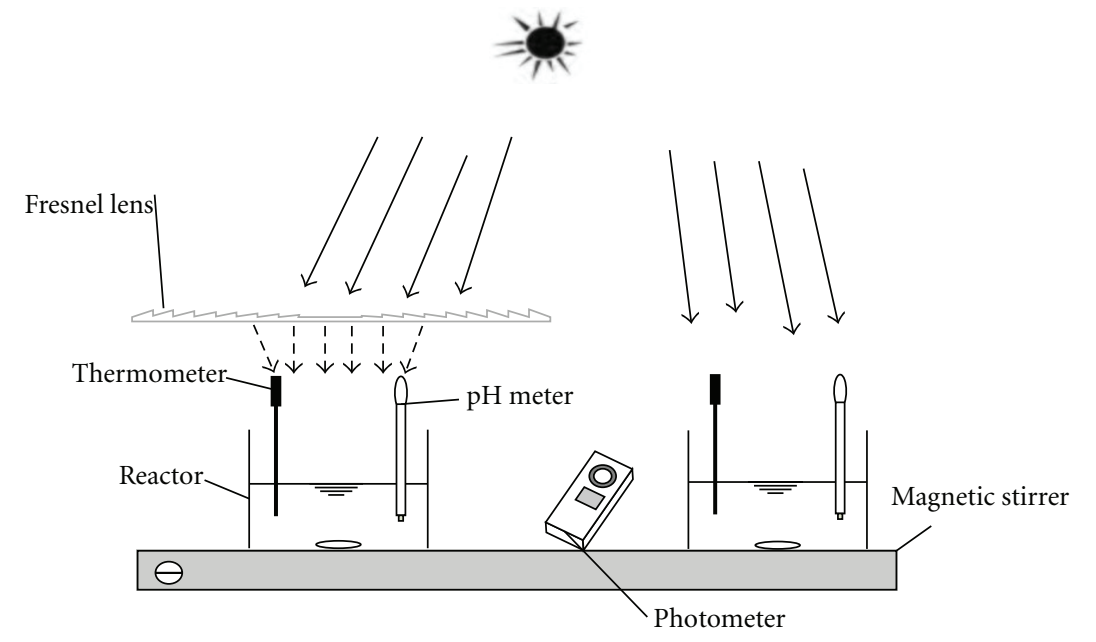

FIgURE 1: Schematic diagram of the solar photoreactor with and without Fresnel lens.

$1 / \mathrm{EC}_{50}$. The $\mathrm{EC}_{50}$ of color filter wastewater was measured, and it was 76 78\%. Toxicity Unit $\left(\mathrm{TU}_{50}\right)$ was, therefore, in the range of $1.25 \sim 1.30$ for color filter wastewater. In this study, the $\mathrm{TU}_{50}$ value was used to trace the change in toxicity of color filter wastewater due to solar photo-Fenton treatment.

\section{Results and Discussion}

3.1. Optimization of Solar Photo-Fenton Treatment of Color Filter Wastewater. On the basis of RSM application, the empirical relationship between the biodegradability of color filter wastewater $(Y)$ and independent variables studied are shown as follows:

$$
\begin{aligned}
Y_{\mathrm{BOD}_{5} / \mathrm{COD}} & \\
= & 0.4770+0.0066 X_{1}+0.0968 X_{2}-0.1251 X_{3} \\
& -0.0374 X_{1}^{2}-0.0291 X_{2}^{2}-0.0084 X_{3}^{2}-0.0795 X_{1} X_{2} \\
& -0.0628 X_{2} X_{3}-0.0565 X_{2} X_{3}, \\
r^{2}= & 0.904 .
\end{aligned}
$$

The regression model (1) had a high value of coefficient of determination $\left(r^{2}>0.90\right)$. This implies that the process efficiency could be predicted properly by the polynomial regression equations under the conditions studied. Based on the model equation, the optimal values of the process parameters were established as under a $\mathrm{pH}$ of 5 , a $\left[\mathrm{H}_{2} \mathrm{O}_{2}\right]_{0} / \mathrm{COD}_{0}$ ratio of $1 \sim 1.35$, and a $\left[\mathrm{H}_{2} \mathrm{O}_{2}\right]_{0} /\left[\mathrm{Fe}^{2+}\right]_{0}$ ratio of 15 for a reaction time of $60 \mathrm{~min}$, which could reach a readily biodegradable level, that is, the biodegradability $\left(\mathrm{BOD}_{5} / \mathrm{COD}\right)$ of wastewater was more than 0.3 . In order to confirm the optimum conditions, five replicates and $t$ test analysis were performed. The results showed that the average of $\mathrm{BOD}_{5} / \mathrm{COD}$ was 0.306 and the $95 \%$ of confidence intervals for $\mathrm{BOD}_{5} / \mathrm{COD}$ was $0.290 \sim 0.322$. Consequently, the credibility of the optimal conditions obtained in this study was acceptable.
3.2. Effect of Fresnel Lens on the Degradation Efficiency of Wastewater. Basically, it was found that the concentrating effect of Fresnel lens for solar energy could result in an increase $2 \sim 3$ times of solar light irradiation and a raising heat irradiation in terms of $15 \sim 30^{\circ} \mathrm{C}$ of wastewater temperature in this study. Figure 1 showed the effect of Fresnel lens on COD and TOC degradation efficiency of color filter wastewater. As shown in Figure 2, an $85 \%$ of COD and a $70 \%$ of TOC degradation of color filter wastewater were achieved with the assistance of Fresnel lens, in contrast to a $48 \%$ of COD and a $32 \%$ of TOC degradation in solar photo-Fenton process with a solar irradiation of $1,000 \mathrm{~W} / \mathrm{m}^{2}$ was observed within $60 \mathrm{~min}$. The decolorization efficiency of color filter wastewater also increased $17 \%$ as using Fresnel lens. Moreover, it was found that the degradation efficiency of color filter wastewater with the use of Fresnel lens at a reaction time of $30 \mathrm{~min}$ was higher than that without the assistance of Fresnel lens at a reaction time of $60 \mathrm{~min}$. This could be due to a higher light irradiation and because water temperature increased the reaction rate between hydrogen peroxide and any form of ferrous/ferric ion, thus increased the rate of generation of oxidizing species such as ${ }^{\bullet} \mathrm{OH}$ radical [10]. A similar phenomenon was also found in the study of Will et al. [11]. Its result indicated that the TOC degradation efficiency of phenol wastewater was $45 \%$ and $55 \%$ for a solar irradiation of $450 \mathrm{~W} / \mathrm{m}^{2}$ and $750 \mathrm{~W} / \mathrm{m}^{2}$, respectively. In addition, the study's results of Rodriguez et al. [12] showed that the degradation efficiency of textile wastewater increased while the temperature of water was improved obviously from $30^{\circ} \mathrm{C}$ to $60^{\circ} \mathrm{C}$ in photo-Fenton process.

To quantitatively analyze the effect of Fresnel lens on degradation of color filter wastewater, a pseudo-first-order model was applied to obtain the rate constants. It was found that both the COD and TOC degradation efficiencies of color filter wastewater with or without Fresnel lens followed the pseudo-first-order reaction kinetics as indicated by high correlation coefficient $\left(r^{2}>0.90\right)$ (Table 3). It was obvious that a significant enhancement for the degradation rate of color filter wastewater was achieved by using Fresnel lens. As 


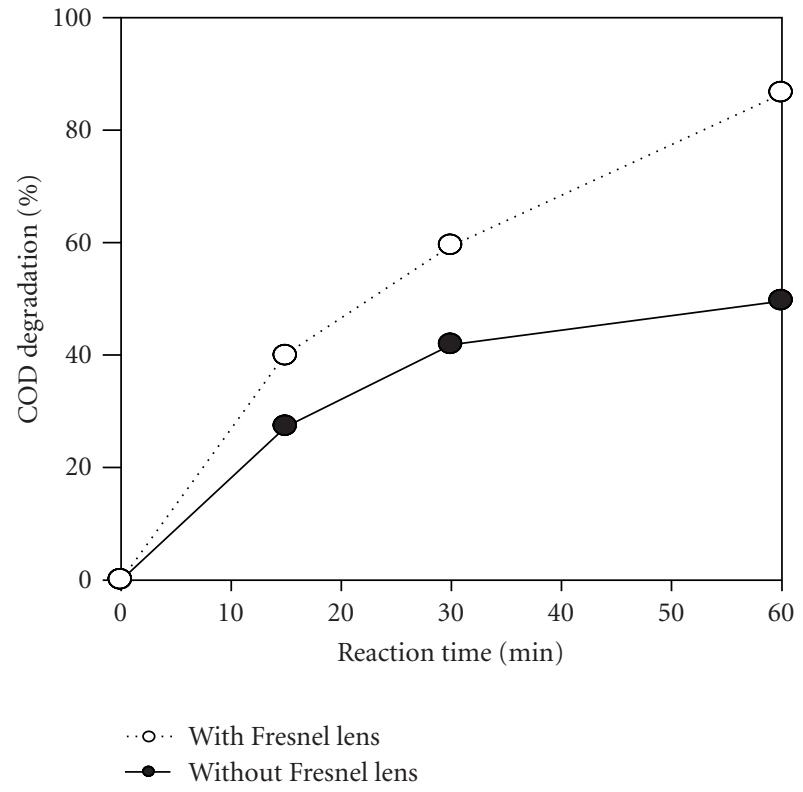

(a)

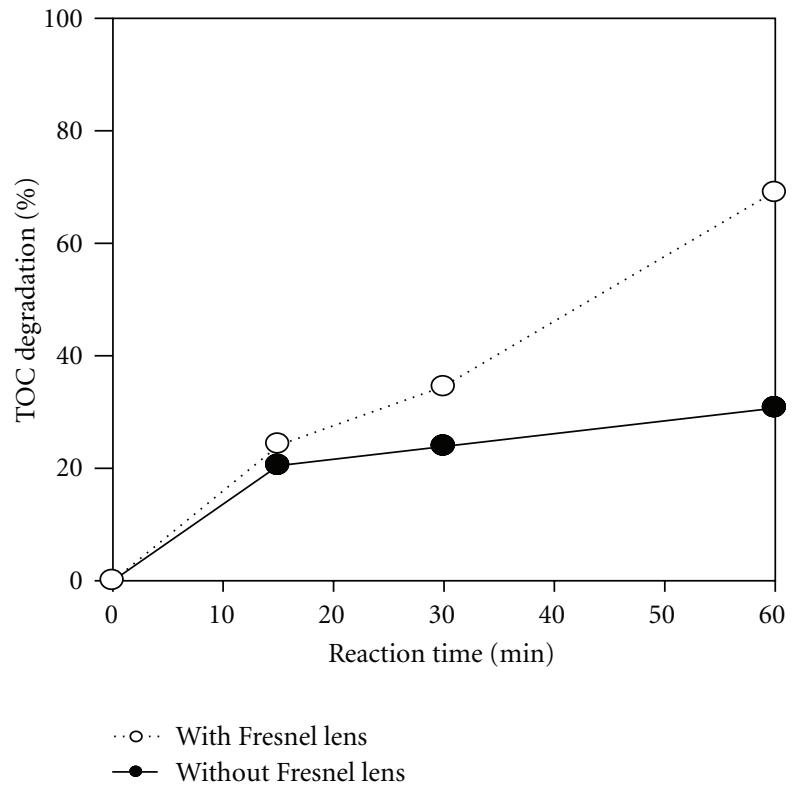

(b)

Figure 2: Effect of Fresnel lens on the degradation efficiency of (a) COD and (b) TOC of color filter wastewater in solar photo-Fenton process (initial $\mathrm{pH}: 5.0 ; \mathrm{H}_{2} \mathrm{O}_{2} / \mathrm{COD}=1.25 \mathrm{~g} / \mathrm{g} ;\left[\mathrm{H}_{2} \mathrm{O}_{2}\right]_{0} /\left[\mathrm{Fe}^{2+}\right]_{0}=15$ ).

TABLE 3: Effect of Fresnel lens on the degradation rate constant of color filter wastewater.

\begin{tabular}{lccc}
\hline Solar Photo-Fenton Process & ${ }^{\mathrm{a}} k_{\mathrm{COD}}, \mathrm{min}^{-1}$ & ${ }^{\mathrm{b}} k_{\mathrm{TOC}}, \mathrm{min}^{-1}$ & ${ }^{\mathrm{c}} \mathrm{UV}_{\mathrm{a}+\mathrm{b}}, \mathrm{W} / \mathrm{m}^{2}$ \\
\hline Without Fresnel lens & $0.0076 \pm 0.00079$ & $0.0032 \pm 0.00050$ & 54.82 \\
With Fresnel lens & $0.0342 \pm 0.00232$ & $0.0208 \pm 0.00170$ & 138.09 \\
\hline
\end{tabular}

* Operation condition: $\mathrm{pH}_{0}$ : 5.0, $1.25 \mathrm{~g} \mathrm{H}_{2} \mathrm{O}_{2} / \mathrm{g} \mathrm{COD},\left[\mathrm{H}_{2} \mathrm{O}_{2}\right]_{0} /\left[\mathrm{Fe}^{2+}\right]_{0}=15$.

${ }^{a} k_{\text {COD }}$ : pseudo-first-order rate constant based on the degradation of COD in solution for $95 \%$ confidence coefficient.

${ }^{\mathrm{b}} k_{\mathrm{TOC}}$ : pseudo-first-order rate constant based on the degradation of TOC in solution for $95 \%$ confidence coefficient.

${ }^{c} \mathrm{UV}_{\mathrm{a}+\mathrm{b}}$ : UV light $(280-400 \mathrm{~nm})$ intensity.

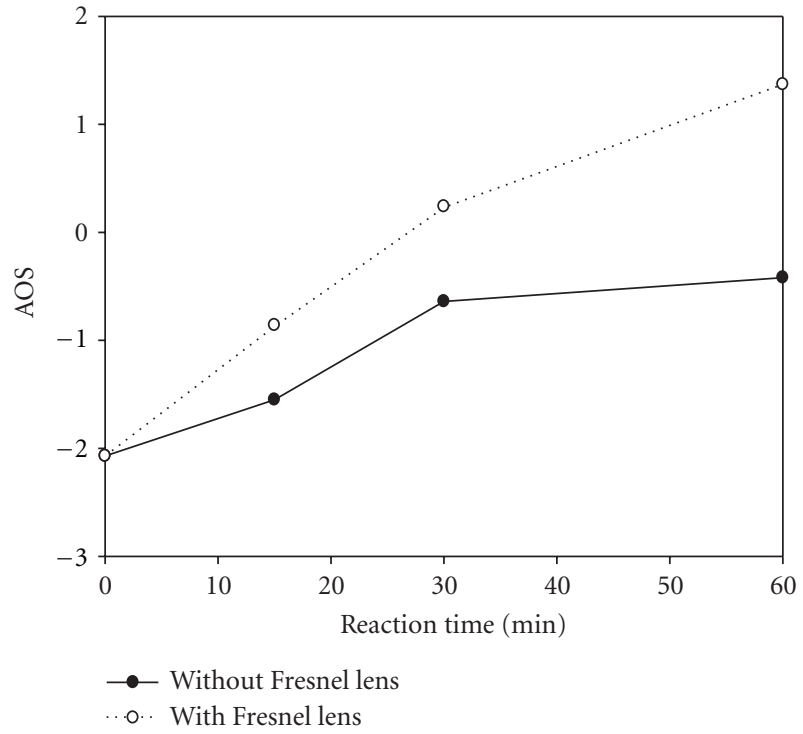

FIGURE 3: Effect of Fresnel lens on AOS of color filter wastewater in solar photo-Fenton process (initial pH: $5.0 ; \mathrm{H}_{2} \mathrm{O}_{2} / \mathrm{COD}=1.25 \mathrm{~g} / \mathrm{g}$; $\left.\left[\mathrm{H}_{2} \mathrm{O}_{2}\right]_{0} /\left[\mathrm{Fe}^{2+}\right]_{0}=15\right)$. the rate constant shown in Table 3 , the COD degradation rate and mineralization rate of color filter wastewater increased a factor of 4.5 and 6.5 , respectively, mainly due to the $U V_{a+b}$ light intensity increasing 2.5 times with assistance of Fresnel lens.

3.3. Effect of Fresnel Lens on the Biodegradability of Wastewater. The degree of oxidation and produced intermediates of color filter wastewater during solar photo-Fenton treatment could affect significantly the biodegradability of solution [13]. Average oxidation state (AOS) could be used to monitor the change in the degree of oxidation [14]. The average oxidation state of the organic carbon was calculated by

$$
\mathrm{AOS}=4-1.5 \times \frac{\mathrm{COD}}{\mathrm{TOC}}
$$

in which the unit of COD and TOC is mol $\mathrm{O}_{2} / \mathrm{L}$ and mol $\mathrm{C} / \mathrm{L}$, respectively. The AOS value indicates how chemical substances in the effluent become more oxidized. A higher AOS value implies a higher degree of oxidation. Theoretically, the AOS has a value of +4 for $\mathrm{CO}_{2}$, the most oxidized state of $\mathrm{C}$, and -4 for $\mathrm{CH}_{4}$, the most reduced state of carbon. As shown in Figure 3, the untreated color 


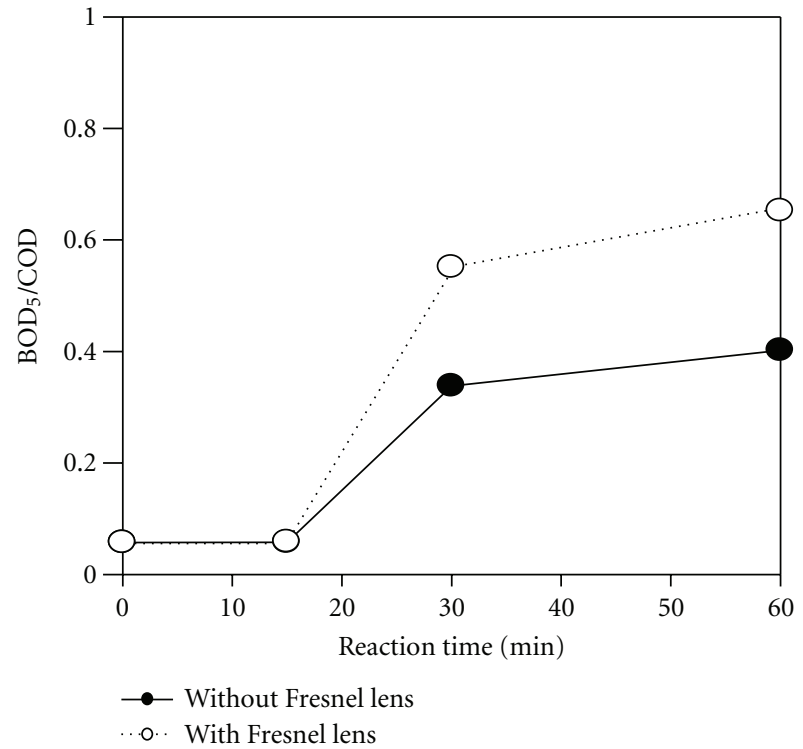

FIgURE 4: Effect of Fresnel lens on the biodegradability of color filter wastewater in solar photo-Fenton process (initial $\mathrm{pH}$ : 5.0; $\left.\mathrm{H}_{2} \mathrm{O}_{2} / \mathrm{COD}=1.25 \mathrm{~g} / \mathrm{g} ;\left[\mathrm{H}_{2} \mathrm{O}_{2}\right]_{0} /\left[\mathrm{Fe}^{2+}\right]_{0}=15\right)$.

filter wastewater has an AOS value of -2.07 and the AOS values increased to 1.37 and -0.42 at a reaction time of 60 min with and without using Fresnel lens, respectively. This result implied that a higher degree of oxidation happened in Fresnel-lens-assisted system. Figure 4 showed the effect of Fresnel lens on $\mathrm{BOD}_{5} / \mathrm{COD}$ of color filter wastewater. It was found that the Fresnel-lens-assisted solar photo-Fenton process could improve furthermore in the biodegradability of color filter wastewater. The required reaction time to reach the criteria of a ready biodegradability of wastewater, in which a $\mathrm{BOD}_{5} / \mathrm{COD}$ value of 0.3 was usually selected, was less as a result for the Fresnel-lens-assisted system.

3.4. Effect of Fresnel Lens on the Microtoxicity of Wastewater. The effect of Fresnel lens on the microtoxicity of color filter wastewater in solar photo-Fenton process was shown in Figure 5. It was found that the microtoxicity of color filter wastewater increased obviously at a reaction time of $15 \mathrm{~min}$, which may be due to more toxic intermediates generated at initial reaction stage. A similar result was also found in the study of González et al. [8]. However, the $\mathrm{TU}_{50}$ value decreased almost to 0 in the Fresnel-lens-assisted system as reaction was proceeding to $60 \mathrm{~min}$, while the solar photoFenton process without Fresnel lens remained a $\mathrm{TU}_{50}$ value of 1.116 .

\section{Conclusion}

With the assistance of Fresnel lens, the efficacy of solar photo-Fenton process enhanced considerably in terms of the COD degradation rate, mineralization rate, and biodegradability of color filter wastewater. In addition, the $\mathrm{TU}_{50}$ value of wastewater was almost diminished after a $60 \mathrm{~min}$ of treatment, whereas the microtoxicity of treated wastewater

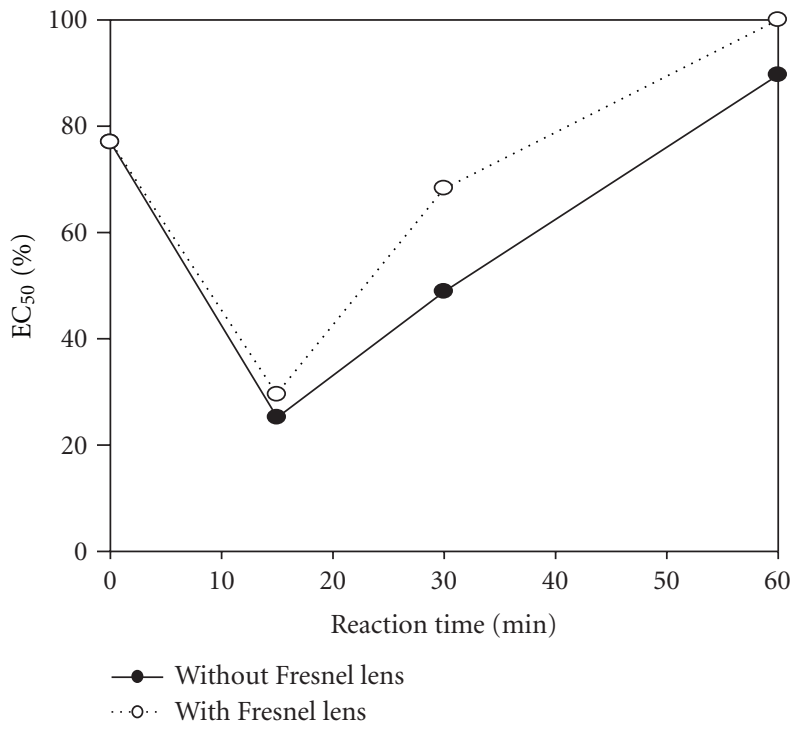

(a)

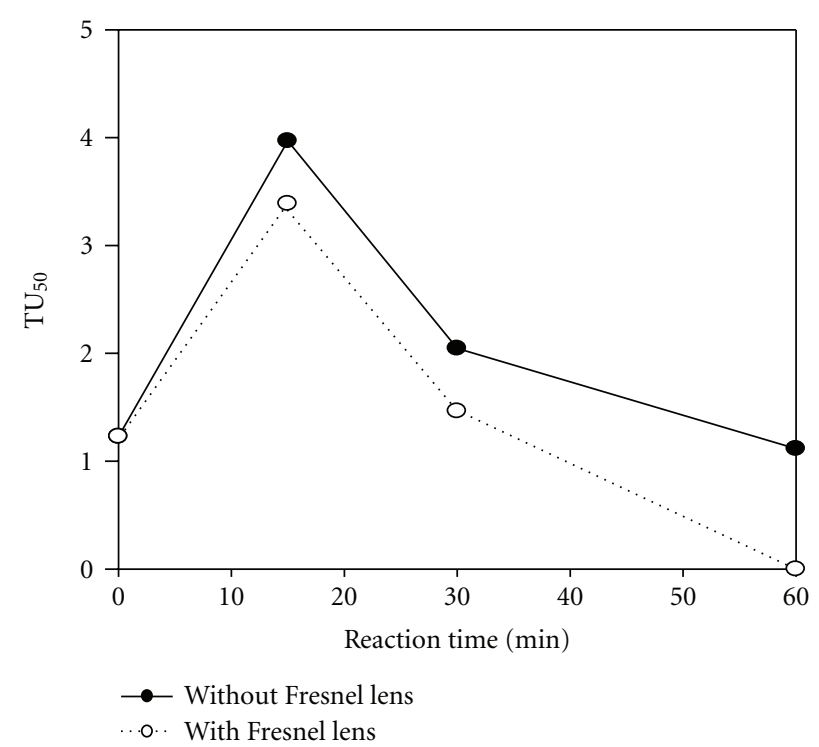

(b)

FIGURE 5: Effect of Fresnel lens on the microtoxicity of color filter wastewater in solar photo-Fenton process (initial $\mathrm{pH}$ : 5.0; $\left.\mathrm{H}_{2} \mathrm{O}_{2} / \mathrm{COD}=1.25 \mathrm{~g} / \mathrm{g} ;\left[\mathrm{H}_{2} \mathrm{O}_{2}\right]_{0} /\left[\mathrm{Fe}^{2+}\right]_{0}=15\right)$.

without the assistance of Fresnel lens remained a $\mathrm{TU}_{50}$ value of 1.166 . This could be mainly due to the concentrated effect of Fresnel lens for solar energy, resulting in an increase of $2 \sim 3$ times of solar light intensity and a raising heat irradiation in terms of $15 \sim 30^{\circ} \mathrm{C}$ of wastewater temperature. Accordingly, solar energy could be concentrated effectively by using Fresnel lens and showed a significant promoting effect on the performance of solar photo-Fenton process for treating color filter wastewater.

\section{Acknowledgment}

The authors are grateful to the National Science Council, Taiwan, for financial support (NSC 98-2221-E-239-004). 


\section{References}

[1] F. Al Momani, O. Gonzalez, C. Sans, and S. Esplugas, "Combining photo-Fenton process with biological sequencing batch reactor for 2,4-dichlorophenol degradation," Water Science and Technology, vol. 49, no. 4, pp. 293-298, 2004.

[2] L. A. Perez-Estrada, S. Malato, A. Aguera, and A. R. Fernandez-Alba, "Degradation of dipyrone and its main intermediates by solar AOPs: identification of intermediate products and toxicity assessment," Catalysis Today, vol. 129, pp. 207-214, 2007.

[3] M. I. Maldonado, P. C. Passarinho, I. Oller et al., "Photocatalytic degradation of EU priority substances: a comparison between $\mathrm{TiO}_{2}$ and Fenton plus photo-Fenton in a solar pilot plant," Journal of Photochemistry and Photobiology A, vol. 185, pp. 354-363, 2007.

[4] S. Malato, P. Fernandez-Ibanez, M. I. Maldonado, J. Blanco, and W. Gernjak, "Decontamination and distinfection of water by solar photocatalysis: recent overview and trends," Catalysis Today, vol. 147, pp. 1-59, 2009.

[5] J. M. Monteagudo and A. Durán, "Fresnel lens to concentrate solar energy for the photocatalytic decoloration and mineralization of orange II in aqueous solution," Chemosphere, vol. 65, no. 7, pp. 1242-1248, 2006.

[6] R. M. Sellers, "Spectrophotometric determination of hydrogen peroxide using potassium titanium(IV) oxalate," The Analyst, vol. 105, no. 1255, pp. 950-954, 1980.

[7] APHA/AWWA/WEF, Standard Methods for the Examination of Water and Wastewater, Washington, DC, USA, 20th edition, 2000.

[8] O. González, C. Sans, and S. Esplugas, "Sulfamethoxazole abatement by photo-Fenton. Toxicity, inhibition and biodegradability assessment of intermediates," Journal of Hazardous Materials, vol. 146, no. 3, pp. 459-464, 2007.

[9] A. S. Koparal, Y. Yavuz, C. Gürel, and Ü. B. Öğütveren, "Electrochemical degradation and toxicity reduction of C.I. Basic Red 29 solution and textile wastewater by using diamond anode," Journal of Hazardous Materials, vol. 145, no. 1-2, pp. 100-108, 2007.

[10] J. H. Sun, S. P. Sun, G. L. Wang, and L. P. Qiao, "Degradation of azo dye Amido black 10B in aqueous solution by Fenton oxidation process," Dyes and Pigments, vol. 74, no. 3, pp. 647652, 2007.

[11] I. B. S. Will, J. E. F. Moraes, A. C. S. C. Teixeira, R. Guardani, and C. A. O. Nascimento, "Photo-Fenton degradation of wastewater containing organic compounds in solar reactors," Separation and Purification Technology, vol. 34, no. 1-3, pp. 51-57, 2004.

[12] M. Rodriguez, V. Sarria, S. Esplugas, and C. Pulgarin, "Photofenton treatment of a biorecalcitrant wastewater generated in textile activities: biodegradability of the photo-treated solution," Journal of Photochemistry and Photobiology A, vol. 151, no. 1-3, pp. 129-135, 2002.

[13] W. S. Kuo and Y. Y. Ho, "Treatment of pesticide rinsate towards reuse by photosensitized Fenton-like process," Water Science and Technology, vol. 62, no. 6, pp. 1424-1431, 2010.

[14] F. Al Momani, "Impact of photo-oxidation technology on the aqueous solutions of nitrobenzene: degradation efficiency and biodegradability enhancement," Journal of Photochemistry and Photobiology A, vol. 179, no. 1-2, pp. 184-192, 2006. 

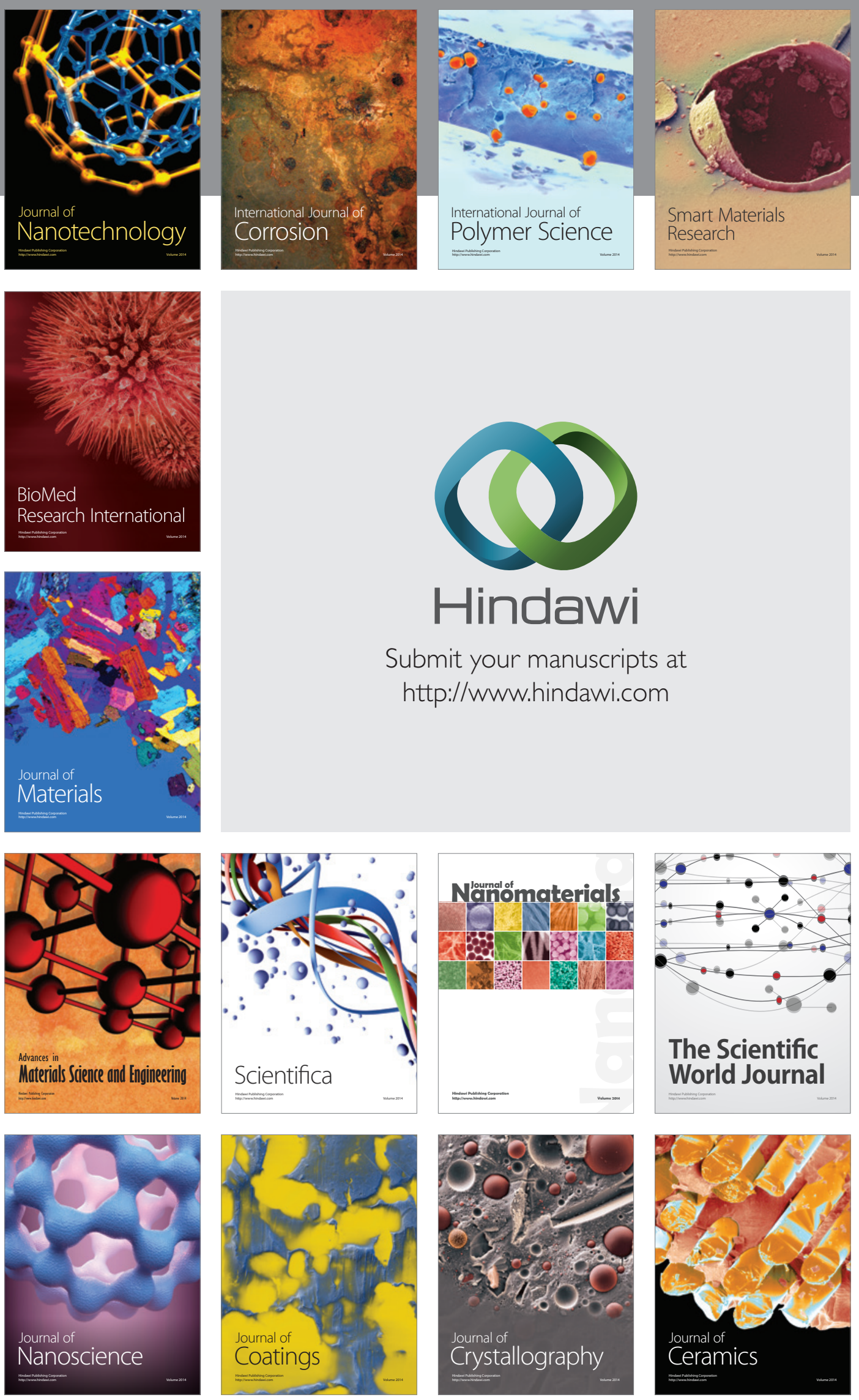

The Scientific World Journal

Submit your manuscripts at

http://www.hindawi.com

\section{World Journal}

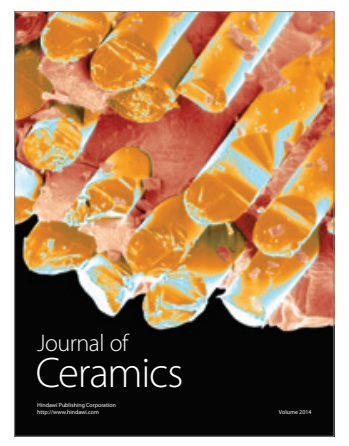

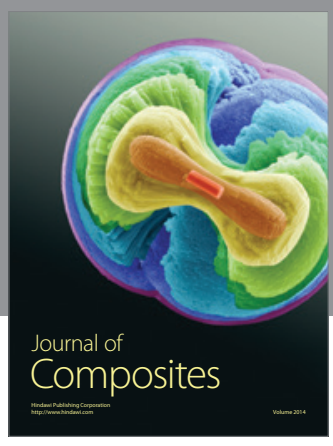
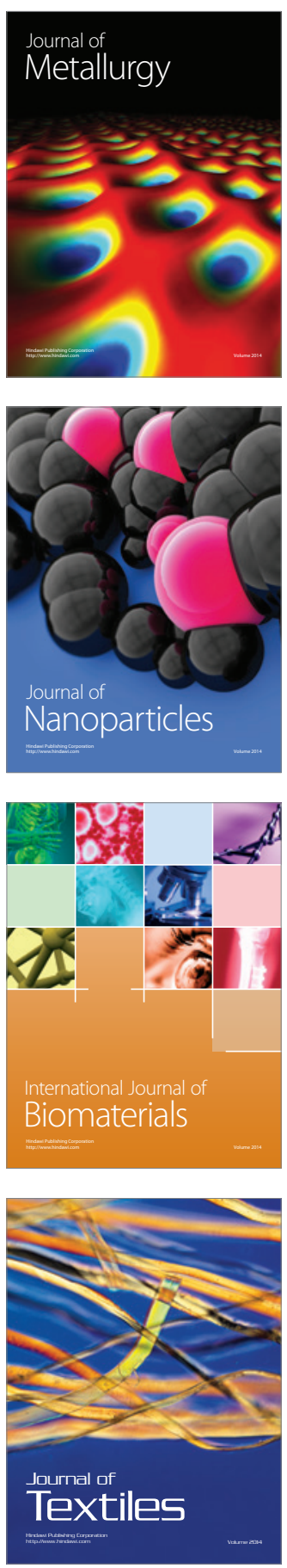